\title{
STUDI DESKRIPTIF IMPLEMENTASI KURIKULUM 2013 UNTUK ANAK TUNARUNGU TINGKAT SEKOLAH DASAR
}

\author{
Lutfi Isni Badiah \\ Universitas PGRI Adi Buana Surabaya \\ lutfiisnibadiah@gmail.com
}

\begin{abstract}
$+\frac{1}{2}$
ABSTRAK

Tujuan dari kegiatan penelitian ini adalah untuk mendeskripsikan implementasi kurikulum 2013 untuk anak tunarungu. Adapun lokasi penelitian adalah di SDLB-B Karya Mulia II Surabaya. Sumber data penelitian adalah guru kelas dan kepala sekolah. Penelitian ini bersifat kualitatif deskriptif. Data dikumpulkan melalui cara: 1) pengamatan, 2) wawancara, dan 3) dokumentasi. Secara keseluruhan, penerapan kurikulum 2013 untuk siswa tunarungu terdapat modifikasi pada aspek materi, metode pengajaran, media pembelajaran dan penilaian. SDLB-B Karya Mulia II Surabaya dalam menerapkan kurikulum 2013 untuk anak didiknya menitikberatkan pada program khusus (progsus) siswa tunarungu yaitu program bina bicara, bina komunikasi persepsi bunyi dan irama (BKPBI), keterampilan dan kewirausahaan. Beberapa kendala dalam implementasi kurikulum 2013 diantaranya adalah: (1) masih kurangnya ketersediaan sarana prasarana dan media, dan (2) tingkat kemampuan siswa yang beragam membuat guru harus lebih memperhatikan pemilihan media, metode, dan strategi pembelajaran untuk siswa tunarungu.
\end{abstract}

Katakunci : kurikulum 2013, sekolah dasar, tunarungu

\section{ABSTRACT}

The purpose of this research activity is to describe the implementation of the 2013 curriculum for deaf children. The research location is in SDLB-B Karya Mulia II Surabaya. Research data sources are classroom teachers and school principals. This research is qualitative descriptive. Data is collected through: 1) observation, 2) interview, and 3) documentation. Overall, the application of the 2013 curriculum for deaf students there was a modification in aspects of the material, teaching methods, learning media and assessment. SDLB-B Karya Mulia II Surabaya in implementing the 2013 curriculum for their students focused on the special program (progsus) for deaf students namely the speech development program, the development of sound and rhythm perception communication (BKPBI), skills and entrepreneurship. Some constraints in the implementation of the 2013 curriculum include: (1) the lack of availability of infrastructure and media, and (2) diverse levels of student ability, making teachers have to pay more attention to the selection of media, methods and learning strategies for deaf students.

Keywords: 2013 curriculum, deaf children, elementary school

\section{PENDAHULUAN}

Kurikulum disusun sebagai alat untuk meraih tujuan dalam proses pendidikan. Tentu saja kurikulum harus selalu diperbaharui seiring dengan tuntutan perkembangan zaman dan kemajuan teknologi agar dapat menghasilkan lulusan yang dibutuhkan oleh masyarakat. Kurikulum 2013 adalah kurikulum terbaru dalam pendidikan di Indonesia. Pada periode sebelumnya, Indonesia menerapkan Kurikulum Tingkat Satuan Pendidikan (KTSP) di semua sekolah. Pada tahun 2013, terjadi penggantian kurikulum dari 
kurikulum KTSP menjadi Kurikulum 2013. Kurikulum ini merupakan hasil pengembangan dari Kurikulum KTSP dengan menitikberatkan pada penilaian tiga aspek. Tiga aspek tersebut adalah aspek pengetahuan (kognitif), aspek sikap (afektif) dan aspek perilaku (psikomotorik) (Yustitia, 2017). Kurikulum 2013 pada tingkat dasar, lebih menitikberatkan pada pendidikan karakter (Mayasari, 2016). Pengembangan kurikulum 2013 ini menitikberatkan pada pengembangan karakter, sehingga diharapkan dapat menghasilkan lulusan yang kreatif, produktif, miliki inovatif, berkarakter dan memiliki daya saing dengan dengan bangsa lain.

Pengembangan kurikulum 2013 tidak hanya berfokus pada siswa normal saja, namun juga mengakomodasi pendidikan untuk anak berkebutuhan khusus (ABK). Hanya saja, pengembangan kurikulum 2013 untuk ABK telah dimodifikasi dan mengalami penyesuaian dengan jenis hambatan, karakteristik dan kemampuan tiap ABK (Susanti \& Mahmudah, 2016). Adapun bentuk modifikasi kurikulum 2013 untuk ABK adalah berupa penyesuaian dalam: 1 ) tujuan pembelajaran, 2) standar isi, 3) strandar proses, dan 4) evaluasi (Putri, 2015). SDLB-B Karya Mulia II Surabaya sebagai sekolah yang menyediakan pendidikan untuk anak tunarungu, sekolah ini juga telah mengimplementasikan kurikulum 2013. Diharapkan dengan implementasi kurikulum 2013 dalam pendidikan untuk anak tunarungu, dapat menjadikan anak tunarungu menjadi insan yang inovatif, produktif, kreatif, dan berkarakter. Sejalan dengan uraian diatas, maka penelitian ini bertujuan untuk mendeskripsikan implementasi kurikulum 2013 untuk anak tunarungu di sekolah dasar, serta hambatan yang dihadapi.

\section{METODE PENELITIAN}

Penelitian diadakan di SDLB-B Karya Mulia II Surabaya, dan sumber datanya adalah guru kelas dan kepala sekolah. Jenis penelitian ini adalah penelitian lapangan yang dijelaskan secara deskriptif. Pengumpulan datanya menggunakan cara pengamatan, wawancara, dan dokumentasi. Sedangkan untuk analisis data dilakukan dengan cara:

1. Pengumpulan dan telaah data

2. Reduksi data (penyederhanaan dan pemusatan data)

3. Penyajian data

4. Verifikasi data

5. Pengambilan kesimpulan.

\section{HASIL PENELITIAN DAN PEMBAHASAN}

1. Implementasi Kurikulum 2013 di SDLB-B Karya Mulia II Surabaya. Implementasi kurikulum 2013 di sekolah ini telah diterapkan sejak tahun pelajaran 2015-2016 mulai dari jenjang kelas 1 sampai kelas 6 (enam). Secara keseluruhan, penerapan kurikulum 
2013 untuk siswa tunarungu di sekolah ini sudah cukup baik, hal ini dapat dilihat pada aspek perencanaan, aspek pelaksanaan dan aspek penilaian. Meskipun dalam rentang penerapannya mengalami beberapa kali modifikasi, terutama pada materi, metode pengajaran, media pembelajaran dan penilaian. Selain itu, juga didukung dengan adanya pengembangan dan persiapan kurikulum yang baik, serta mendapatkan dukungan dari tenaga pengajar dan kepala sekolah.

Pada aspek perencanaan telah terlihat pada rencana pelaksanaan pembelajaran yang disusun oleh guru telah disesuaikan dengan buku panduan kurikulum 2013 untuk satuan pendidikan khusus. Perangkat pembelajaran yang telah dibuat oleh guru, sebelumnya ditelaah terlebih dahulu oleh kepala sekolah. Kepala sekolah kemudian memberi masukan jika perangkat pembelajaran yang dibuat oleh guru ini masih ada kekurangan.

Pada aspek pelaksanaan juga terdapat prosedur pembelajaran scientific, yakni bertanya, mengamati, dan menyimpulkan. Guru juga telah menggunakan media yang menarik bahkan juga menggunakan laptop dan LCD. Hal ini untuk mendukung apabila guru mengunakan video interaktif pembelajaran dalam mengajar dan mendukung dalam proses mengamati. Beberapa materi yang dirasa oleh guru terlalu tinggi indikatornya, maka dilakukan modifikasi. Seperti contohnya, pada materi mengarang, untuk anak tunarungu yang memiliki kosa kata terbatas, terutama untuk kelas rendah, maka guru perlu memodifikasi dengan menurunkan indikatornya atau mengganti materi lain yang setara.

Pada aspek penilaian, sekolah ini menerapkan penilaian secara berkala, dengan meliputi 3 aspek, yakni aspek afektif, aspek kognitif dan aspek psikomotorik. Pada penilaian sikap, difokuskan pada sikap disiplin, bertanggungjawab, bekerja sama dan percaya diri. Untuk penilaian pada aspek kognitif, menggunakan tes lisan dan tes tertulis. Sedangkan pada penilaian psikomotorik, guru lebih banyak menggunakan portofolio. Selain itu, guru juga mempunyai catatan harian untuk setiap anak. Fungsi catatan harian ini adalah untuk memantau perkembangan atau progres dari siswa tunarungu. Hasil penilaian ini kemudian dilaporkan dalam raport setiap semester. Raport ini melaporkan hasil capaian belajar anak tunarungu dalam bentuk uraian pada setiap kompetensi. Secara keseluruhan, proses penilaian yang diterapkan telah sesuai dengan standar 
penilaian kurikulum 2013 yang bersifat autentik dan deskriptif.

Pihak sekolah selalu mendorong guru untuk aktif terlibat dalam kegiatan pelatihan/workshop mengenai kurikulum 2013. SDLB-B Karya Mulia II Surabaya dalam menerapkan kurikulum 2013 untuk anak didiknya menitikberatkan pada program khusus (progsus) siswa tunarungu yaitu program bina bicara, BKPBI, keterampilan dan kewirausahaan. Tujuannya adalah agar siswa tunarungu dapat hidup mandiri selepas dari sekolah tersebut.

2. Hambatan kurikulum 2013 untuk siswa tunarungu.

Berdasarkan hasil observasi dan wawancara, disimpulkan bahwa terdapat beberapa hambatan, diantaranya adalah masih kurangnya ketersediaan sarana prasarana dan media, serta bermacam-macamnya tingkat kemampuan siswa tunarungu di dalam kelas. Hal ini membaca konsekuensi pada guru untuk lebih memperhatikan karakteristik masing-masing siswa ketika memilih metode dan media pembelajaran. Menurut narasumber, ketersediaan media masih belum mencukupi. Pembelajaran scientific menuntut guru untuk lebih banyak untuk bisa mengeksplorasi benda-benda di sekeliling anak untuk bisa membangkitkan rasa ingin tahu peserta didik. Apalagi ketika kegiatan mengamati, guru harus bisa menghadirkan media yang tidak menimbulkan persepsi ganda bagi anak tunarungu. Ketersediaan buku guru dan buku siswa untuk anak tunarungu juga menjadi kendala tambahan.

Kendala lain yang menurut guru juga penting adalah beragamnya tingkat kemampuan berpikir anak tunarungu satu sama lain di dalam kelas. Anak tunarungu tentunya mengalami gangguan komunikasi, yang juga mempengaruhi kemampuan belajarnya. Karakteristik lain yang dimiliki oleh anak tunarungu akibat dari hambatan yang dimilikinya ini diantaranya: 1) mereka memiliki kelemahan dalam memahami lambang dan aturan bahasa, 2) tidak mengenal lambang atau kode atau nama dari setiap benda, peristiwa, kegiatan dan perasaan, dan 3) tidak memahami sistem tata bahasa baku (Hernawati, 2007). Untuk mengatasi hal ini, tidak jarang guru menggunakan berbagai macam media dan media pembelajaran yang berbeda sekaligus agar kegiatan mengamati dalam pembelajaran scientific.

\section{SIMPULAN}

Secara keseluruhan, penerapan kurikulum 2013 di SDLB-B Karya Mulia II Surabaya sudah cukup baik. Dalam 
rentang penerapannya mengalami beberapa kali modifikasi, terumata pada materi, metode pengajaran, media pembelajaran dan penilaian. Pada aspek perencanaan telah terlihat pada RPP yang disusun oleh guru. Adapun penyusunannya telah sesuai dengan prosedur pada buku panduan kurikulum 2013 untuk satuan pendidikan khusus. Pada aspek pelaksanaan juga terdapat prosedur pembelajaran scientific, yakni bertanya, mengamati, dan menyimpulkan. Beberapa materi yang dirasa oleh guru terlalu tinggi indikatornya, maka dilakukan modifikasi.

Pada aspek penilaian di SDLB-B Karya Mulia II Surabaya ini meliputi sikap, pengetahuan dan keterampilan. Sekolah ini dalam menerapkan kurikulum 2013 untuk anak didiknya menitikberatkan pada program khusus (progsus) untuk siswa tunarungu yaitu program bina bicara, BKPBI, keterampilan dan kewirausahaan. Hal ini bertujuan agar siswa tunarungu dapat hidup mandiri selepas dari sekolah tersebut. Beberapa kendala dalam implementasi kurikulum 2013 untuk siswa tunarungu di sekolah ini diantaranya adalah masih kurangnya ketersediaan sarana prasarana dan media, serta bermacam-macamnya tingkat kemampuan siswa tunarungu di dalam kelas sehingga guru harus lebih memperhatikan pemilihan media, metode, dan strategi pembelajaran untuk siswa tunarungu.

\section{DAFTAR PUSTAKA}

Hernawati, T. 2007. Pengembangan Kemampuan Berbahasa dan Berbicara Anak Tunarungu. Jassi Anakku, 7(1), 101-110.

Mayasari. 2016. Implementasi Kurikulum 2013 Pada Anak Berkebutuhan Khusus (ABK): Studi Kasus SD Muhammadiyah Sapen Yogyakarta. INKLUSI: Journal of Disability Studies, 3(1), 1-18. https://doi.org/10.14421/ijds.0 30101

Mulyasa, E. 2013. Pengembangan dan Implementasi Kurikulum. PT. Remaja Rosdakarya.

Putri, I. D. 2015. Implementasi Kurikulum 2013 bagi Peserta Didik Berkebutuhan Khusus pada Mata Pelajaran Matematika di SMP Negeri 4 Sidoarjo. Universitas Negeri Surabaya.

Susanti, L., \& Mahmudah, S. 2016. Implementasi Kurikulum 2013 Pada Anak Tunagrahita di SLB AC. Jurnal Pendidikan Khusus UNESA, 8(2).

Yustitia, V. 2017. Kemampuan
Analisis Mahasiswa PGSD
Terhadap Tujuan
Pembelajaran
Kognitif Pada Matar Kuliah
Perencanaan Pembelajaran SD.
Scholaria, 7(1), 83-93.

